\title{
Genetic Transformation of the Obligate Parasite Plasmodiophora brassicae
}

\author{
J. Feng, Sheau-Fang Hwang, and S. E. Strelkov
}

First and second authors: Crop Diversification Centre North, Alberta Agriculture and Rural Development, Edmonton, AB, T5Y 6H3, Canada; and third author: Department of Agricultural, Food and Nutritional Science, University of Alberta, Edmonton, AB, T6G 2P5, Canada.

Accepted for publication 25 March 2013.

\begin{abstract}
Feng, J., Hwang, S.-F., and Strelkov, S. E. 2013. Genetic transformation of the obligate parasite Plasmodiophora brassicae. Phytopathology 103:1052-1057.

A protocol for genetic transformation of the obligate parasite Plasmodiophora brassicae, causal agent of clubroot of crucifers, was developed. In this protocol, protoplast preparation was superseded with lithium acetate treatment and the selection step was omitted. In two independent experiments, germinating resting spores of $P$. brassicae were transformed by two fungal expression vectors containing either a green fluorescent protein $(g f p)$ gene or a hygromycin resistance $(h p h)$ gene. Putative

quantitative PCR (qPCR), and genome walking conducted on selected transformants indicated that the transforming DNA was intergraded into the $P$. brassicae genome. Transcript of $h p h$ but not $g f p$ was detected by reverse-transcription qPCR from selected transformants. From all galls produced by transformants, no GFP activity could be identified. Verified transformants were inoculated on canola and new galls were generated. PCR and qPCR analyses based on these galls indicated that transforming DNA was still resident in $P$. brassicae. This is the first report on genetic transformation of $P$. brassicae. The information and data generated from this study will facilitate research in multiple areas of the clubroot pathosystem.
\end{abstract} transformants were produced from both transformations, with $\approx 50 \%$ of the obtained galls containing resting spores from which transforming DNA could be detected by polymerase chain reaction (PCR). PCR,
Additional keywords: molecular techniques, pathogenicity.
Plasmodiophora brassicae Woronin is an obligate biotrophic protist causing clubroot on canola (Brassica napus) and other cruciferous crops. This disease is known to occur in $>60$ countries and results in a $10-15 \%$ reduction in yields on a global scale (8). In western Canada, clubroot of canola has emerged as one of the most important diseases of this crop in less than a decade (16). Crop rotation is currently recommended as the major control strategy (9). However, because the pathogen can persist in the soil for as long as 20 years (26), crop rotation and other cultural management practices do not necessarily provide satisfactory levels of control, particularly in heavily infested fields. The application of fungicides as a soil drench can significantly reduce clubroot severity but is not economical for canola in western Canada (15), where the costs of application would exceed the increased returns expected from improved yields and oil quality. The most promising management approach has been the deployment of clubrootresistant cultivars of canola; however, resistance will have to be well managed to ensure its longevity (18).

A major reason for the unsatisfactory control of clubroot is the poor understanding of the pathogenicity of $P$. brassicae. Information on how the pathogen causes disease is needed for the rational development and utilization of effective control strategies. However, the biotrophic nature of $P$. brassicae precludes the application of most techniques currently used in studies of other pathosystems. Indeed, there is very limited information on the genetic makeup of $P$. brassicae, with only small numbers of expressed sequence tags (ESTs) and protein sequences available in GenBank.

Corresponding author: S.-F. Hwang; E-mail address: sheau-fang.hwang @ gov.ab.ca

http://dx.doi.org/10.1094/PHYTO-01-13-0010-R

(c) 2013 The American Phytopathological Society
There are also very few functionally characterized genes reported (11).

The application of novel technologies will undoubtedly facilitate research on the clubroot pathosystem. Therefore, in the present study, we attempted to manipulate $P$. brassicae genes by genetic transformation. Two major observations from previous works stimulated the initiation of this project. First, horizontal gene transfer seems not uncommon in $P$. brassicae. Bryngelsson et al. (4) reported that the protist accommodated a piece of $B$. napus DNA during each infection cycle. Another piece of DNA from $B$. rapa was also found to be resident in the $P$. brassicae genome (S. E. Strelkov, unpublished data). That these evolutionary events could be detected by designed experiments infers that their frequency is high enough to be artificially repeated. Second, within the $P$. brassicae life cycle, after resting spore germination and before initiation of root hair infection, there is a short period of time in which $P$. brassicae is vulnerable to the environment and can be manipulated in vitro. Thus, the objectives of the present study were to (i) develop a protocol for $P$. brassicae transformation and (ii) demonstrate that the protocol can produce transformants that have had the transforming DNA integrated into their genome and that this transformants can pass the transforming DNA to the next generation of the pathogen.

\section{MATERIALS AND METHODS}

Chemicals and standard techniques. All chemicals were purchased from Fisher Scientific Canada (Ottawa, ON, Canada) unless otherwise specified. Primers (Table 1) were synthesized by Integrated DNA Technologies (Coralville, IA). Polymerase chain reaction (PCR) and quantitative (q)PCR were conducted in an Eppendorf Mastercycler thermal cycler (Eppendorf, Hamburg, Germany) and a StepOnePlus Real-Time PCR System (Life 
Technologies, Carlsbad, CA), respectively. Sequencing was conducted by the Department of Biological Sciences, University of Alberta (Edmonton, AB, Canada). Green fluorescent protein (GFP) activity in the transformants was examined with a Zeiss AX10 fluorescence microscope (Carl Zeiss, Oberkochen, Germany). Other molecular techniques, if not specified, were performed according to the protocols described by Sambrook and Russell (22).

Plant materials and the $\boldsymbol{P}$. brassicae strain. Transformation was conducted on the P. brassicae strain Led09 (11). Canola 'Westar' was used as host. Galls that developed on roots of Westar after infection by Led09 or its transformants in a greenhouse were collected and kept at $-20^{\circ} \mathrm{C}$. All inoculations were conducted on 7-day-old Westar seedlings that were prepared according to Feng et al. (13).

Collection of resting spores. Galls were homogenized in $10 \%$ (wt/vol) sucrose in a blender. The slurry was passed through eight layers of cheesecloth and the suspension was centrifuged in a $50-\mathrm{ml}$ tube at $50 \times g$ for $5 \mathrm{~min}$. The supernatant was transferred into a new tube and centrifuged at $2,000 \times g$ for $5 \mathrm{~min}$. The resulting pellet had two distinct layers: the lower black layer consisted of soil particles and the upper white-to-brownish layer of resting spores (4). The upper layer was suspended in $5 \mathrm{ml}$ of water by gentle pipetting and transferred into a new tube containing $40 \mathrm{ml}$ of water. After centrifugation at 2,000 $\times \mathrm{g}$ for $5 \mathrm{~min}$, the supernatant was discarded. Spores in the pellet were adjusted to $5 \times 10^{8}$ spores $/ \mathrm{ml}$ and surface disinfected with colistin sulfate at $1.0 \mu \mathrm{g} / \mathrm{ml}$ and vancomycin hydrochloride at $1.0 \mu \mathrm{g} / \mathrm{ml}$ (both from Sigma-Aldrich Canada, Oakville, ON, Canada) at $20^{\circ} \mathrm{C}$ in the dark for $24 \mathrm{~h}$. After removal of the antibiotics by washing twice with $40 \mathrm{ml}$ of distilled water, the spores were used for transformation or DNA extraction or as inoculum.

Transforming DNA. Two fungal expression vectors were used for transformation: pGC1-1 (21), which contains a hygromycin resistance $(h p h)$ gene under the control of the Glomerella cingulata gpdA promoter, and pFGFP (10), which contains a gfp gene under the control of the Aspergillus nidulans gpdA promoter. Both vectors were maintained in Escherichia coli strain JM109 (Promega Corp., Madison, WI).

Transformation. Transformation was conducted twice. In the first transformation, the collected resting spores in 50-ml tubes were adjusted to $5 \times 10^{8}$ spores $/ \mathrm{ml}$ in water and kept at $20^{\circ} \mathrm{C}$ with gentle shaking for $6 \mathrm{~h}$. The tubes were centrifuged at $2,000 \times g$ for $5 \mathrm{~min}$ and the pellet was suspended in $0.1 \mathrm{M} \mathrm{LiOAc}$ at $5 \times 10^{9}$ spores $/ \mathrm{ml}$. Aliquots $(3 \mathrm{ml})$ of the suspension were incubated at $37^{\circ} \mathrm{C}$ in $50-\mathrm{ml}$ tubes with gentle shaking. After $30 \mathrm{~min}$, plasmid DNA of pGC1-1 and pFGFP (both are circular DNA at $800 \mu \mathrm{g}$ in a volume of $200 \mu \mathrm{l}$ ) were added to each tube. The tubes were incubated on ice for $1 \mathrm{~h}$ and then $10 \mathrm{ml}$ of polyethylene glycol (PEG) 8000 solution $(30 \%$ in $50 \mathrm{mM} \mathrm{CaCl}$ ) was added. After incubation at $20^{\circ} \mathrm{C}$ for $1 \mathrm{~h}$, hygromycin $\mathrm{B}$ at a final concentration of $100 \mu \mathrm{g} / \mathrm{ml}$ or the same amount of water was added into the tubes. The tubes were incubated at $20^{\circ} \mathrm{C}$ for $3 \mathrm{~h}$ and then centrifuged at 2,000 $\times g$ for $5 \mathrm{~min}$. The pellet was washed three times with $40 \mathrm{ml}$ of water for each wash, followed by centrifugation at $2,000 \times g$ for $5 \mathrm{~min}$. The pellet was suspended in water at $5 \times 10^{8}$ spores/ml and was immediately used for inoculation.

In the second transformation, $200 \mu \mathrm{g}$ of pFGFP plasmid DNA was linearized with the restriction enzyme $\mathrm{XhoI}$ and the digestion mixture $(300 \mu \mathrm{l})$ was used as transforming DNA. Hygromycin B was excluded and PEG-treated spores were incubated at $20^{\circ} \mathrm{C}$ for $4 \mathrm{~h}$.

Two mock transformations (CKs) were also conducted in both transformation experiments. In CK1, transformation was performed as described above but the spore sample was autoclaved before adding transforming DNA. After adding the DNA and incubating the mixture at $20^{\circ} \mathrm{C}$ for $\approx 2 \mathrm{~h}$, the sample was washed three times with $40 \mathrm{ml}$ of water as described above. The pellet was suspended in $10 \mathrm{ml}$ of water and the suspension was used for inoculation. In CK2, the transformation protocol was followed except that the transforming DNA was replaced with the same amount of water. In both CK1 and CK2, no hygromycin was applied.

Inoculation. The seedlings were inoculated with the wild-type, mock-transformed, or transformed spores by immersing the roots in the suspension for $10 \mathrm{~min}$. The plants were transferred into 500-ml cups containing autoclaved Sunshine mix number 4 soil (Sun Gro Horticulture, Vancouver, BC, Canada). The cups were kept in a greenhouse maintained at 24 and $18^{\circ} \mathrm{C}$ (day and night, respectively) with a 16-h photoperiod, and watered from the bottom every second day with tap water at $\mathrm{pH} 6.4$ (adjusted with $\mathrm{HCl}$ ). After 35 or 42 days, the plants were dug out of the potting mixture and the roots were washed with tap water. Galls were collected and stored at $-20^{\circ} \mathrm{C}$.

DNA and RNA extraction. DNA extraction was performed using a modified cetyltrimethylammonium bromide (CTAB) method. Galled or healthy root samples were washed with excess water and ground using a mortar and pestle in $1.5 \mathrm{ml}$ of CTAB buffer (1\% CTAB; 10 mM EDTA, pH 8.0; 100 mM Tris- $\mathrm{HCl}$, $\mathrm{pH} 7.5 ; 1 \mathrm{M} \mathrm{NaCl} ; 1 \%$ n-lauroylsarcosine; and RNase A at $100 \mu \mathrm{g}$ $\left.\mathrm{ml}^{-1}\right)$. The slurry $(1 \mathrm{ml})$ was transferred into a $1.5-\mathrm{ml}$ tube and centrifuged at $14,000 \times g$ for $2 \mathrm{~min}$. The supernatant was transferred into a new tube and repeatedly extracted with $0.5 \mathrm{ml}$ of phenol-chloroform until the aqueous phase became clear. The aqueous phase was supplemented with Tris-EDTA buffer to $750 \mu \mathrm{l}$ and subjected to a final extraction with $0.5 \mathrm{ml}$ of chloroform. The aqueous phase $(500 \mu \mathrm{l})$ was transferred into a new tube and the DNA was precipitated by adding $600 \mu \mathrm{l}$ of isopropanol. All DNA samples were dissolved in water at a concentration of $50 \mathrm{ng} / \mu \mathrm{l}$. Total RNA was extracted from galls with a Qiagen RNeasy Plant Mini Kit (Chatsworth, CA), following the manufacturer's instructions. The obtained RNA was cleaned up with the Qiagen RNase-Free DNase Set.

PCR, qPCR, and reverse-transcription qPCR. Except in the genome walking analysis, all PCRs were run in a final volume of $20 \mu \mathrm{l}$ in the Promega master mix with $0.25 \mu \mathrm{M}$ each primer and $100 \mathrm{ng}$ of template; for all primers, the annealing temperature was $56^{\circ} \mathrm{C}$, the elongation time was $45 \mathrm{~s}$, and the cycle number was 35 . qPCR was run in a final volume of $25 \mu$ using $0.25 \mu \mathrm{M}$ each primer with the SYBR Green Core Reagents Kit (Life Technologies). Reverse-transcription (RT)-qPCR was performed with the Promega GoTaq 2-step RT-qPCR system. In both qPCR and RTqPCR, the $P$. brassicae Actin2 gene (GenBank accession number: AAR88383) was used for normalization and the comparative cycle threshold method was used to analyze the data according to Schmittgen and Livak (23).

Genome walking. Genome walking was conducted based on two transformants using the APAgene Gold Genome Walking Kit (Bio S\&T, Montreal, QC, Canada) according to the manufacturer's instructions. PCR was conducted using primers GSPa, $\mathrm{GSPb}$, and GSPc (Table 1) and the primers included in the kit.

TABLE 1. Primers used in this study

\begin{tabular}{|c|c|c|}
\hline Primer & Sequences (forward/reverse) & $\begin{array}{l}\text { Amplicon } \\
\text { size (bp) }\end{array}$ \\
\hline $\mathrm{HPH}-\mathrm{F}_{1} / \mathrm{R}_{1}$ & aagaatctcgtgctttcagcttc/gtcggcatctactctattccttt & 945 \\
\hline $\mathrm{HPH}-\mathrm{F}_{2} / \mathrm{R}_{2}$ & atttcggctccaacaatgtc/gatgttggcgacctcgtatt & 104 \\
\hline GFP-F ${ }_{1} / \mathrm{R}_{1}$ & tctgactagtaaaggagaagaa/tatagttcatccatgccatgtgt & 714 \\
\hline GFP-F $F_{2} / R_{2}$ & gagggatacgtgcaggagag/aggatgtttccgtcctcctt & 143 \\
\hline $\mathrm{GSPa}^{\mathrm{a}}$ & aattggcgatggecctgtcettttac & $\ldots$ \\
\hline $\mathrm{GSPb}^{\mathrm{a}}$ & cagacaaccattacctgtccacaca & $\ldots$ \\
\hline $\mathrm{GSPc}^{\mathrm{a}}$ & aaagatcccaacgaaaagagagac & $\ldots$ \\
\hline Actin-F/R & gggacatcaccgactacctg/actgetccgagttggacatc & 150 \\
\hline GW1-F/R & atgggaagaatgacggtgaa/caggcagtacctgttccaca & 354 \\
\hline GW2-F/R & aacccgcagacaaattgaag/tgaaaacggtccatacagca & 318 \\
\hline
\end{tabular}

a These primers were gene-specific primers (GSP) used in genome walking. 
After the second nested PCR, the largest band for each transformant was TA cloned with the pGEM T Easy vector system (Promega Corp.). Sequencing was conducted using the M13 forward primer. Similarity searches for the obtained sequences were conducted with the basic local alignment search tool (Blast) against the National Center for Biotechnology Information (NCBI) database (http://blast.ncbi.nlm.nih.gov) using Blastn and Blastx.

\section{RESULTS}

Transformations produced putative transformants. In the first transformation, pFGFP and pGC1-1 were used to transform P. brassicae with (Trt 1) or without (Trt 2) hygromycin B. For each treatment, 60 canola seedlings were inoculated with transformed spores. After 42 days, 25 galls from 56 surviving plants for Trt 1 and 20 galls from 53 surviving plants for Trt 2 were obtained. DNA was extracted from each of these galls, three healthy plants produced by CK1, as well as three galls produced by CK2. Against these DNAs, PCR was conducted to verify the presence of an $h p h$ fragment and a $g f p$ fragment using primer pairs HPHF1/R1 and GFP-F1/R1, respectively. Among the 24 (1 was excluded because of insufficient amount of DNA) samples in treatment 1 , the $g f p$ and $h p h$ fragments were present in 20 and 12 samples, respectively; among the 20 samples in Trt 2, the respective numbers were 19 and 8 . Two conclusions could be drawn from these data: (i) P. brassicae was genetically transformed in a very high efficiency and (ii) hygromycin was not functional in P. brassicae.
Two bands each for $g f p$ and $h p h$ were cut from the gel (Fig. 1A) and the purified DNA was sequenced. These sequences shared $100 \%$ identifies with the sequences between the forward and reverse primers of pFGFP or pGC1-1, indicating that the PCR products were derived from the transforming DNA.

A second transformation was conducted to verify the transformation efficiency. Linearized pFGFP was used as the transforming DNA and the hygromycin treatment was omitted. After 42 days, 64 galls were obtained from 87 plants. PCR analysis with the primer pair GFP-F2/R2 indicated that the specific fragment was present in 27 of 64 DNA samples (Fig. 1B).

Transcript of $\boldsymbol{h p h}$ but not $g \boldsymbol{f} \boldsymbol{p}$ was detected from transformants. Total RNA was extracted from eight samples, each consisting of four galls from the first transformation. RT-qPCR was conducted to verify the expression of $h p h$ and $g f p$ using primer pairs HPH-F2/R2 and GFP-F2/R2, respectively. The $h p h$ transcript was detected from five RNA samples at very low levels, with the highest one at $1.54 \%$ relative to the Actin2 transcript (Table 2). In contrast, no $g f p$ transcript could be identified from all samples. Moreover, no GFP activity (green fluorescence) was found in resting spore samples prepared from all the collected galls.

Transforming DNA is associated with $P$. brassicae DNA. In the PCR screening of the transformants (Fig. 1), no band was amplified from either CK1 or CK2, indicating that the transforming DNA was not already present in the plant or P. brassicae and that there was no transforming DNA on the plant or $P$. brassicae surface or in the soil. To further confirm this, galls of all transformants produced from the second transformation were pooled and homogenized in a blender. Resting spores were prepared from

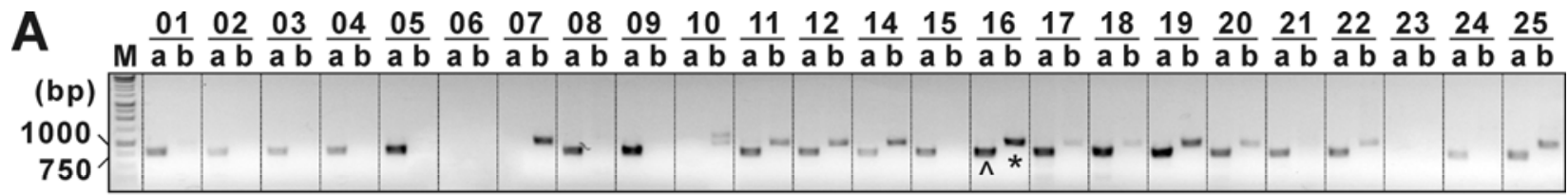

$\begin{array}{llllllllllllllllllllllllll}26 & 27 & 28 & 29 & 30 & 31 & 32 & 33 & 34 & 35 & 36 & 37 & 38 & 39 & 40 & 41 & 42 & 43 & 44 & 45 & c k 1 & c k 2\end{array}$

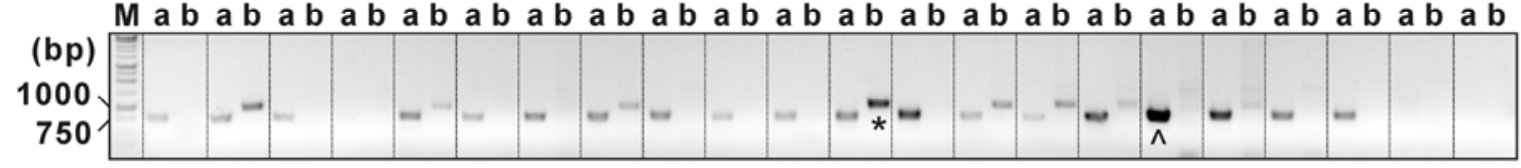

B
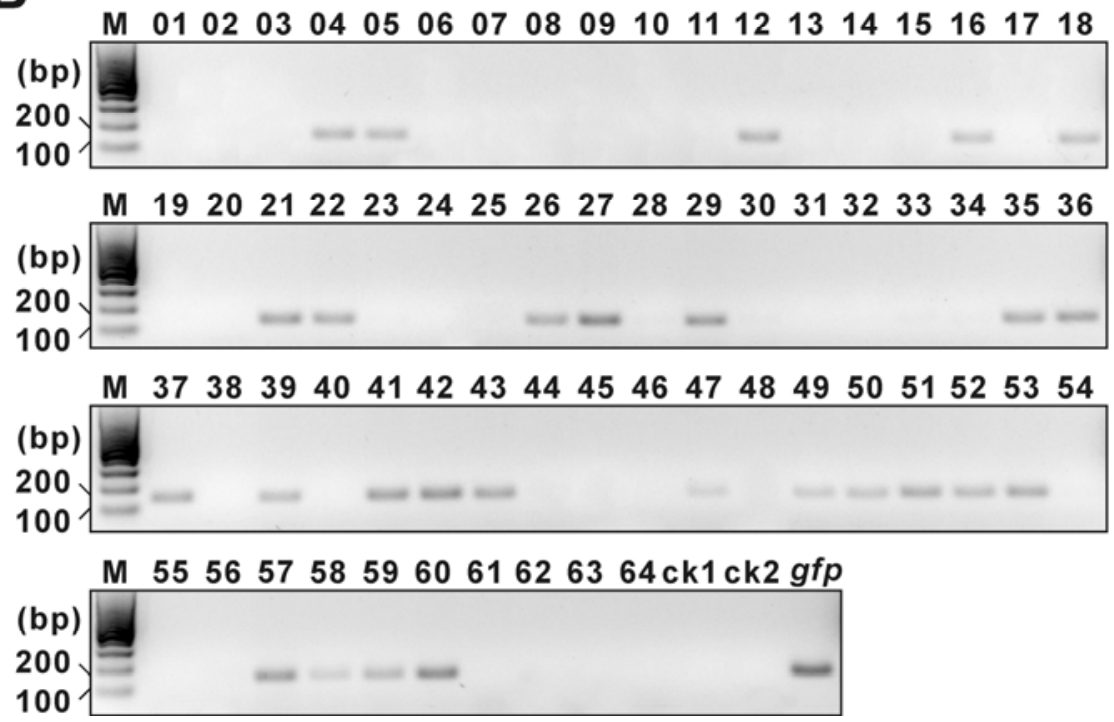

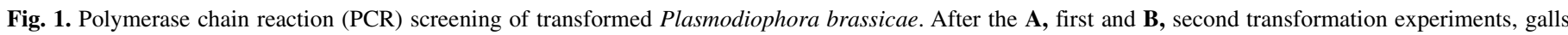

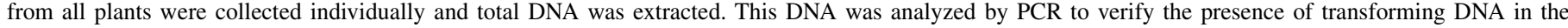

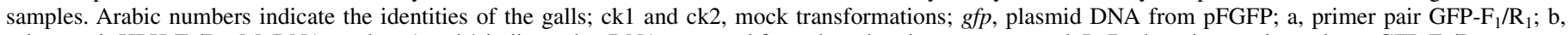
primer pair $\mathrm{HPH}-\mathrm{F}_{1} / \mathrm{R}_{1} ; \mathrm{M}, \mathrm{DNA}$ marker; ${ }^{\wedge}$ and $*$ indicate that DNA extracted from these bands was sequenced. In $\mathrm{B}$, the primer pair used was GFP-F $/ \mathrm{R}_{2}$. 
a portion of the slurry. Samples from both the slurry and the resting spores received two treatments: treated and untreated with DNase for $2 \mathrm{~h}$ at $37^{\circ} \mathrm{C}$. DNA was extracted from all of these samples and subjected to PCR analysis with the primer pair GFPF2/R2, which amplified a specific band from all DNA samples (Fig. 2A); this confirmed the presence of the transforming DNA in vivo.

To confirm that the transforming DNA was transferred into $P$. brassicae rather than other organisms associated with the plant or P. brassicae (or resident in the soil), another PCR assay was conducted. Gall slurry $(1 \mathrm{ml})$ was prepared from each of three transformants from the first transformation. From each of the three slurry samples, $50 \mu \mathrm{l}$ was used to inoculate $900 \mu \mathrm{l}$ of LuriaBertani (LB) medium. The LB cultures were shaken at $200 \mathrm{rpm}$ at $37^{\circ} \mathrm{C}$, while the slurries were kept at $-20^{\circ} \mathrm{C}$. After $20 \mathrm{~h}$, all LB cultures became cloudy as a result of the proliferation of bacteria. DNA was extracted from the gall slurries and LB cultures. Following PCR analysis with the primer pair GFP-F2/R2, positive and stronger bands were obtained from the slurry DNA relative to the LB DNA (Fig. 2B), confirming that the transforming DNA was in $P$. brassicae rather than in the bacteria.

The above results were further confirmed by qPCR. Compared with Actin2, the relative amount of $g f p$ was consistent across the four DNA samples extracted from galls or spores with or without DNase treatment (Fig. 2C). For two of the three transformants, the relative amount of $g f p$ between the DNA samples prepared from the galls and LB cultures was positively associated with those of Actin2 (Fig. 2D).

Transforming DNA is integrated into the $P$. brassicae genome. Genome walking (GW) was conducted based on transformant number 9 from the first transformation and number 21 from the second transformation. The largest fragment produced from each GW was TA cloned and the insert in selected colonies was sequenced. The sequence produced from transformant number 9 contained 355 bp of pFGFP DNA followed by 550 bp of DNA. Blastx indicated that this 550-bp sequence shares identity $(\mathrm{E}$ value $=3 \mathrm{e}-27)$ with a P-type ATPase from Phytophthora infestans. The sequence produced from transformant number 21 contained 24 bp of the pFGFP DNA followed by 442 bp of DNA with no homolog in the databases. Primers GW1-F/R and GW2F/R were designed based on these two new sequences and used to amplify bands from DNA samples prepared from various sources of $P$. brassicae and healthy canola plants. For both sequences, bands of the expected sizes were amplified from $P$. brassicae but not from the healthy canola (Fig. 3A and B). These results indicate that the two sequences were derived from $P$. brassicae. The two sequences were submitted to GenBank with accession numbers JX986516 and JX986517.

Transforming DNA is vertically transferred to the next generation. The introduction of DNA into cells does not neces-

TABLE 2. Expression of transforming genes in selected transformants

\begin{tabular}{|c|c|c|c|c|c|}
\hline \multirow[b]{2}{*}{ Sample } & \multirow[b]{2}{*}{ Galls $^{\mathrm{a}}$} & \multicolumn{3}{|c|}{ Detection of transcript ${ }^{b}$} & \multirow[b]{2}{*}{ Expression } \\
\hline & & Actin2 & $h p h$ & $g f p$ & \\
\hline 1 & $2,3,4,5$ & + & + & - & $0.97 \pm 0.37$ \\
\hline 2 & $11,12,14,16$ & + & + & - & $0.58 \pm 0.08$ \\
\hline 3 & $17,18,19,20$ & + & + & - & $0.27 \pm 0.04$ \\
\hline 4 & $22,23,24,25$ & + & + & - & $0.52 \pm 0.15$ \\
\hline 5 & $28,29,31,32$ & + & - & - & $\ldots$ \\
\hline 6 & $37,38,39,40$ & + & + & - & $1.54 \pm 0.19$ \\
\hline 7 & $42,43,44,45$ & + & - & - & $\ldots$ \\
\hline 8 & $\mathrm{CK} 2$ & + & - & - & $\ldots$ \\
\hline
\end{tabular}

a Numbers indicate the galls obtained from the first transformation that were pooled for RNA extraction.

b Actin2, hygromycin resistance $(h p h)$, and green fluorescent protein ( $g f p$ ) genes.

c Expression level (\%) of $h p h$ relative to the Actin2 gene (mean \pm standard deviation, $n=3$ ). sarily imply that this DNA can be passed on to the next generation. To confirm this, galls from all transformants produced from the second transformation were pooled and a sample of the prepared resting spores was used to inoculate canola seedlings. After 35 days, 22 galls were obtained from 50 plants. The $g f p$ fragment was amplified with the primer pair GFP-F2/R2 from 10 of these 22 galls (Fig. 4). This result was further confirmed by qPCR, which detected the $g f p$ DNA from eight selected galls (Fig. 4).

\section{DISCUSSION}

Theoretical basis of the transformation. An essential factor in the advancement of recombinant DNA techniques has been the development of genetic transformation systems. In this way, it is possible to manipulate the genome of organisms, correlating in vitro studies of purified DNA with biological consequences in vivo. Genetic transformation has been established in many plantpathogenic microbes. Historically, three strategies have been utilized for transformation (25): protoplast-based transformation, electroporation, and biolistics. Protoplast-based transformation is

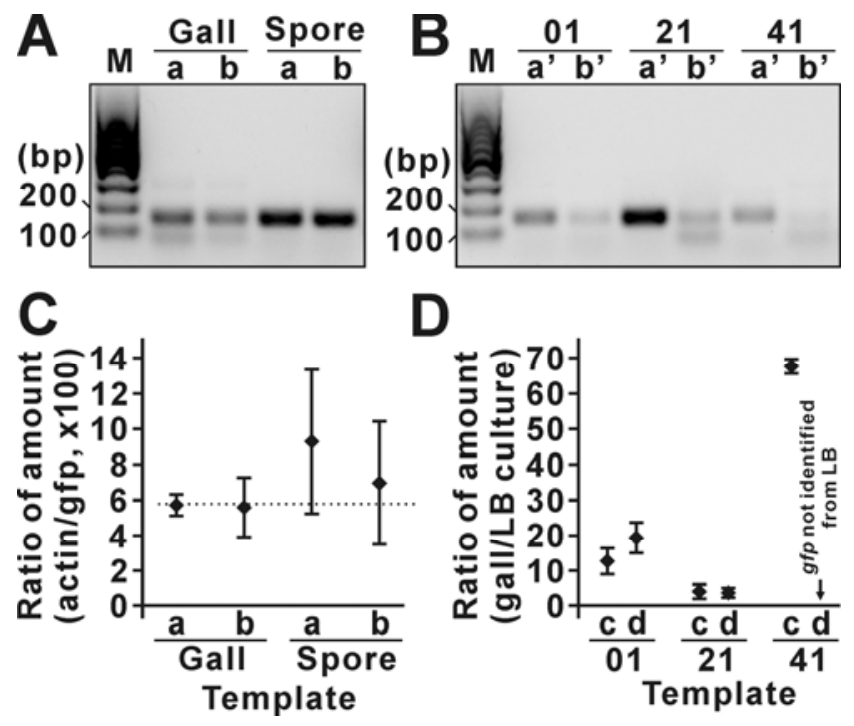

Fig. 2. Confirmation of transformation by polymerase chain reaction (PCR) with primers green fluorescent protein (GFP) $-\mathrm{F}_{2} / \mathrm{R}_{2}$ and quantitative (q)PCR with primers Actin-F/R and GFP- $\mathrm{F}_{2} / \mathrm{R}_{2}$. A and $\mathbf{C}$, Galls from the second transformation were pooled, and DNA was then extracted from the gall slurry and purified resting spores without (a) or with (b) DNAse treatment. DNA samples were analyzed by A, PCR and C, qPCR. B and D, Slurry was prepared from three galls $(01,21$, and 41$)$ from the first transformation. A sample of the slurry was cultured in Luria-Bertani (LB) medium overnight. DNA was extracted from the slurry (a') and LB culture (b'). DNA samples were analyzed by B, PCR and D, qPCR; c, the Actin2 gene; d, the gfp gene; M, DNA marker.
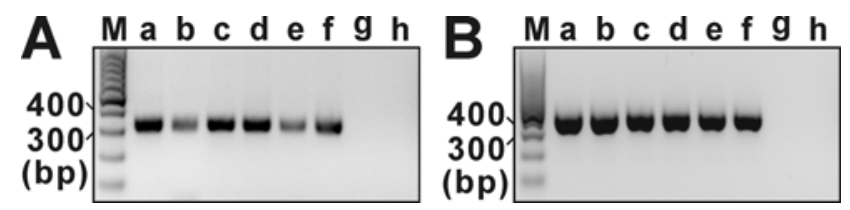

Fig. 3. Confirmation of the integration of the transforming DNA in the Plasmodiophora brassicae genome by genome walking. DNA from one transformant from either the $\mathbf{A}$, first or $\mathbf{B}$, second transformation was used for genome walking. The largest band obtained was sequenced and the sequence information used to design the primer pairs GW1-F/R (A) and GW2-F/R (B). Polymerase chain reaction analysis of the $P$. brassicae or plant DNA derived from the various sources was conducted with these primers. Lanes a to d, the same DNA samples as in Figure 2A, from left to right; lanes e and f, DNA from individual galls collected from a greenhouse (e) and field (f); lanes $g$ and $\mathrm{h}$, DNA from individual healthy plants collected from a greenhouse $(\mathrm{g})$ and field (h); lane M, DNA marker. 
among the most commonly used approaches, especially in culturable pathogens. Genetic transformation of biotrophic plant pathogens is difficult, mainly as a consequence of the fact that both regeneration and selection of transformants require culturing on artificial media which, in most biotrophic microbes, is not possible or very difficult. Other challenges include the fact that the recipient materials are either difficult to collect or are inevitably contaminated with host tissue.

To our knowledge, the genetic transformation of $P$. brassicae has not been reported. However, the observation that it is relatively easy to obtain large numbers of $P$. brassicae resting spores and that these spores can germinate in vitro suggests that this pathogen merits the application of transformation. More importantly, during its life cycle, $P$. brassicae does have a very short vulnerable stage (17), after primary zoospore geminated from the resting spore and before entering the root hair, which may provide an opportunity for the transfer of foreign DNA into the cell. If this is the case, the recipient primary zoospore would carry the foreign DNA to the stage of root hair infection. The pathogen formed primary plasmodia in root hairs and, therein, nuclear divisions occurred for the first time in its life cycle (17). During DNA replication, the foreign DNA might have a chance to integrate into the pathogen genome which, in other words, implies that the real transformation event happened in planta during primary infection, albeit the transformation was done in vitro before infection.

The transformation protocol. The protocol described in the current study allowed production of transformants in repeated experiments. Although resting spores were the material from which transformation was initiated, primary zoospores might be the real recipients of the transforming DNA. First, the cell wall of resting spores is thicker and more robust than the cell wall of primary zoospores. Second, during the process of resting spore preparation, a period of $\approx 36 \mathrm{~h}$ passed from the release of the resting spores from the galled root tissue to the time that the spore mixture encountered the transforming DNA. This period of time was sufficiently long to allow for the germination of the resting spores to produce primary zoospores.

The protocol bypassed the preparation of protoplasts and, instead, lithium acetate was used to stimulate the cells to be competent. The lithium acetate procedure has been successfully applied to the transformation of Neurospora crassa (7), Coprinus cinereus (3), and Ustilago violacea (2). However, the exact mechanism by which lithium cations assist the passage of DNA into cells does not seem to be well understood.

The addition of a high concentration of PEG following the initial period of exposure to DNA is a step common to most of the protoplast transformation protocols. The effect of PEG is to cause the treated cells to clump, and this may facilitate the trapping of DNA (14). In our protocol, PEG was added along with calcium chloride. Calcium cations can help in the uptake of DNA,

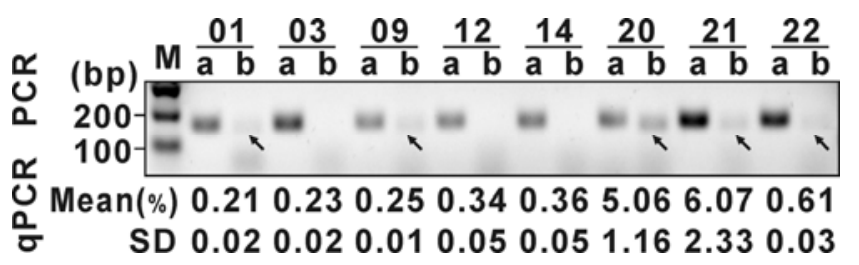

Fig. 4. Confirmation of the inheritance of transforming DNA in the Plasmodiophora brassicae transformants. Galls of all the transformants from the second transformation were pooled and the derived resting spores were used to inoculate canola seedlings. DNA was extracted from the resulting galls and subjected to polymerase chain reaction (PCR) and quantitative (q)PCR analyses to screen for the presence of the transforming DNA. Arabic numbers indicate the identities of galls; $a$, primer pair Actin-F/R; b, primer pair green fluorescent protein (GFP)- $\mathrm{F}_{2} / \mathrm{R}_{2}$. Arrows emphasize the presence of the $g f p$ bands. In the qPCR analysis, primers a and $\mathrm{b}$ were used. Mean and standard deviation (SD), amount of $g f p$ DNA relative (\%) to Actin2 DNA (mean $\pm \mathrm{SD}$, $n=3)$. although they have been reported to have a negative effect on $P$. brassicae resting spore germination (8). Thus, the calcium was applied later than in other protocols.

Effect of hygromycin and expression of $\boldsymbol{h p h}$ and $\boldsymbol{g} \boldsymbol{f p}$. In the first transformation, we expected that the non-hygromycin treatment would produce more galls than the hygromycin treatment, due to the possibility that a portion of the spores was killed by hygromycin. However, this was not the case, indicating that the hygromycin was not functional. Although it is possible that the concentration of hygromycin used was too low for P. brassicae, the question was not examined further. Furthermore, because the integration of transforming DNA can only occur during root hair infection when hygromycin was removed, the $h p h$ vector pGC1-1 was not used in the second transformation.

The expression of $h p h$ was detected from transformants at a very low level. In contrast, neither $g f p$ expression nor GFP activity could be detected. Both $g f p$ and $h p h$ are under the control of fungal $g p d A$ promoters. It is likely that the fungal promoters could not be recognized well by the trans-element or the transcription machinery of $P$. brassicae. More studies are needed to illustrate the detailed reasons. However, construction of an expression vector that consists of selection marker genes driven by a $P$. brassicae promoter will be an interesting follow-up study.

Efficiency of the transformation. Although the results from the qPCR analysis (Figs. 2C and 4) confirmed the transformants, it also indicated that the absolute amount of transforming DNA ( $g f p$ ) was hundreds of times lower than Actin2 DNA in the transformants. Thus, it can be inferred that the transformed cells represent only a small portion of all of the $P$. brassicae cells contained within a gall. Nevertheless, given the fact that no selection was applied, the transformation efficiency in $P$. brassicae was still high compared with that in other plant pathogens.

As an intracellular obligate biotroph, $P$. brassicae interacts with host cellular materials intimately during infection. Furthermore, as a plasmodium, the pathogen is naked (without a cell wall). This provides an ideal opportunity for both the plant and the pathogen to interchange their genetic materials. The high transformation efficiency, as revealed in the present study, suggests that the uptake of foreign DNA is also common in P. brassicae under natural conditions. Furthermore, the high transformation efficiency observed in this study may help to explain the seemly controversial reports from different groups in which the same EST sequences were identified from both $P$. brassicae and the host plants; for example, among the 76 P. brassicae ESTs (NCBI BioSample ID: LIBEST_020565) identified by Bulman et al. (6) from Arabidopsis root galls, 5 are identical to ESTs (LIBEST_021825) derived from $B$. rapa (19). The ability to accept foreign DNA may also be related to the unusual variability seen in $P$. brassicae field populations. Single-spore lineages taken from $P$. brassicae field isolates display considerable differences in pathogenicity and DNA structure $(5,20,24,27)$.

Significance of the present study. Among the pathogens causing major plant diseases, $P$. brassicae represents one that invades the host with an absolutely intracellular life style. Considering this feature and the importance of clubroot worldwide, $P$. brassicae should be studied as a model organism. However, the obligate biotrophic style and the difficulty of obtaining pure pathogen materials have prevented the application of many techniques used in other pathosystems. The infection process is not clearly understood and studies of the pathogen at the "-omics" level are completely lacking. That $P$. brassicae can be genetically transformed sheds light on this unusual situation. Once a promoter that is functional in $P$. brassicae is identified, whole-cell and protein labeling and target gene knockout will become applicable. We expect that the results obtained from the current study will stimulate additional molecular studies on this pathosystem.

The ease with which $P$. brassicae becomes competent to foreign DNA may facilitate the ability of this pathogen to obtain 
new genes by horizontal transfer from other organisms. If under directional selection, these genes will be maintained in the $P$. brassicae genome and fulfill certain functions across the whole population. Such genes could include new pathogenicity or virulence factors contributing to disease severity, genes to defeat plant resistance genes, and genes involved in detoxifying the active components of pesticides. The results from the present study suggest that rapid changes in the genetic structure of $P$. brassicae populations are possible.

Successful transformation of $P$. brassicae also provides a model for the transformation of other obligate biotrophs. There is no reason to predict that a microorganism cannot be transformed simply because of its biotrophic nature.

Future studies. It was unfortunate that, in the current study, we could not identify any transformant with GFP activity. This, as discussed above, likely resulted from the absence of a promoter that was well functional in $P$. brassicae. In another study, we identified $P$. brassicae genes that were highly expressed in resting spores and during infection (12). The promoters of these genes may be good candidates for the construction of gene expression vectors suitable for $P$. brassicae transformation. The development of a $g f p$-tagged $P$. brassicae strain will be a useful tool to study the infection process in this pathosystem.

The transformation protocol will be further optimized. First, upon the identification of suitable antibiotic and promoter that functions in $P$. brassicae, a dual-culture protocol will be tested, in which $P$. brassicae will be transformed with the vector containing the antibiotic resistance genes and then inoculated onto Arabidopsis plants that carry the resistance genes against the same antibiotic. The plants will be grown on medium supplemented with the antibiotic. With this protocol, any galls obtained will theoretically be transformants. Second, previous studies indicated that $P$. brassicae has a short saprotrophic stage; on Ringer's medium complemented with live bacteria, $P$. brassicae resting spores can geminate to primary zoospores and subsequently produce plasmodia (1). A study will be conducted to verify this and the culturing will be integrated into future transformation experiments, which will allow the selection of transformants.

\section{ACKNOWLEDGMENTS}

We acknowledge funding support from the Alberta Crop Industry Development Fund, Canola Agronomic Research Program (Alberta Canola Producers Commission, Manitoba Canola Growers Association, SaskCanola, and the Canola Council of Canada), and the Canola Science Cluster (Agriculture and Agri-Food Canada/Canola Council).

\section{LITERATURE CITED}

1. Arnold, D. L., Blakesley, D., and Clarkson, J. M. 1996. Evidence for the growth of Plasmodiophora brassicae in vitro. Mycol. Res. 100:535-540.

2. Bej, A. K., and Perlin, M. G. 1989. A high efficiency transformation system for the basidiomycete Ustilago violacea employing hygromycin resistance and lithium-acetate treatment. Gene 80:171-176.

3. Binninger, D. M., Skrzynia, C., Pukkila, P. J., and Casselton, L. A. 1987. DNA-mediated transformation of the basidiomycete Coprinus cinereus. EMBO J. 6:835-840

4. Bryngelsson, T., Gustafsson, M., Gréen, B., and Lind, C. 1988. Uptake of host DNA by the parasitic fungus Plasmodiophora brassicae. Physiol. Mol. Plant Pathol. 33:163-171.

5. Buczacki, S. T., Toxopeus, H., Mattusch, P., Johnston, T. D., Dixon, G. R., and Hobolth, G. R. 1975. Study of physiological specialization in Plas- modiophora brassicae: Proposals for attempted rationalisation through an international approach. Trans. Br. Mycol. Soc. 65:295-303.

6. Bulman, S., Siemens, J., Ridgway, H. J., and Conner, A. J. 2006. Identification of genes from the obligate intracellular plant pathogen, Plasmodiophora brassicae. FEMS Microbiol. Lett. 264:198-204.

7. Dhawale, S. S., Paietta, J. V., and Marzluf, G. A. 1984. A new rapid and efficient transformation procedure for Neurospora crassa. Curr. Genet. 8:77-79.

8. Dixon, G. R. 2009. The occurrence and economic impact of Plasmodiophora brassicae and clubroot disease. J. Plant. Growth Regul. 28:194-202.

9. Donald, C., and Porter, I. 2009. Integrated control of clubroot. J. Plant. Growth Regul. 28:289-303.

10. Feng, J., Bhadauria, V., Liu, G., Selvaraj, G., Hughes, G. R., and Wei, Y. 2011. Analysis of the promoter region of the gene LIP1 encoding triglyceride lipase from Fusarium graminearum. Microbiol. Res. 166:618-628.

11. Feng, J., Hwang, R., Hwang, S. F., Strelkov, S. E., Gossen, B. D., Zhou, Q., and Peng, G. 2010. Molecular characterization of a serine protease Pro1 from Plasmodiophora brassicae that stimulates resting spore germination. Mol. Plant Pathol. 11:503-512.

12. Feng, J., Hwang, S. F., and Strelkov, S. E. 2013. Assessment of gene expression profiles in primary and secondary zoospores of Plasmodiophora brassicae by dot blot and real-time PCR. Microbiol. Res. 168:518524.

13. Feng, J., Xiao, Q., Hwang, S. F., Strelkov, S. E., and Gossen, B. D. 2012. Infection of canola by secondary zoospores of Plasmodiophora brassicae produced on a nonhost. Eur. J. Plant Pathol. 132:309-315.

14. Fincham, J. R. S. 1989. Transformation in fungi. Microbiol. Rev. 53:148170 .

15. Hwang, S. F., Cao, T., Xiao, Q., Ahmed, H. U., Manolii, V. P., Turnbull, G. D., Gossen, B. D., Peng, G., and Strelkov, S. E. 2012. Effects of fungicide, seeding date and seedling age on clubroot severity, seedling emergence and yield of canola. Can. J. Plant Sci. 92:1175-1186.

16. Hwang, S. F., Strelkov, S. E., Feng, J., Gossen, B. D., and Howard, R. J. 2012. Plasmodiophora brassicae: A review of an emerging pathogen of the Canadian canola (Brassica napus) crop. Mol. Plant Pathol. 13:105113.

17. Kageyama, K., and Asano, T. 2009. Life cycle of Plasmodiophora brassicae. J. Plant. Growth Regul. 28:203-211.

18. Leboldus, J. M., Manolii, V. P., Turkington, T. K., and Strelkov, S. E. 2012. Adaptation to Brassica host genotypes by a single-spore isolate and population of Plasmodiophora brassicae (clubroot). Plant Dis. 96:833838.

19. Lee, S. C, Lim, M. H., Kim, J. A., Lee, S. I., Kim, J. S., Jin, M., Kwon, S. J., Mun, J. H., Kim, Y. K., Kim, H. U., Hur, Y., and Park, B. S. 2008. Transcriptome analysis in Brassica rapa under the abiotic stresses using Brassica 24K oligo microarray. Mol. Cells. 26:595-605.

20. Manzanares-Dauleux, M. J., Divaret, I., Baron, F., and Thomas, G. 2001. Assessment of biological and molecular variability between and within field isolates of Plasmodiophora brassicae. Plant Pathol. 50:165-173.

21. Rikkerink, E. H. A., Solon, S. L., Crowhurst, R. N., and Templeton, M. D. 1994. Integration of vectors by homologous recombination in the plant pathogen Glomerella cingulata. Curr. Genet. 25:202-208.

22. Sambrook, J., and Russell, D. W. 2001. Molecular Cloning: A Laboratory Manual, 3rd ed. Cold Spring Harbor Laboratory Press, Cold Spring Harbor, NY.

23. Schmittgen, T. D., and Livak, K. J. 2008. Analyzing real-time PCR data by the comparative $C_{\mathrm{T}}$ method. Nat. Protocols 3:1101-1108.

24. Some, A., Manzanares, M. J., Laurens, F., Baron, F., Thomas, G., and Rouxel, F. 1996. Variation for virulence on Brassica napus L. amongst Plasmodiophora brassicae collections from France derived from singlespore isolates. Plant Pathol. 45:432-439.

25. Tuiz-Díez, B. 2002. Strategies for the transformation of filamentous fungi. J. Appl. Microbiol. 92:189-195.

26. Wallenhammar, A. C. 1996. Prevalence of Plasmodiophora brassicae in a spring oilseed rape growing area in central Sweden and factors influencing soil infestation levels. Plant Pathol. 45:710-719.

27. Xue, S., Cao, T., Howard, R. J., Hwang, S. F., and Strelkov, S. E. 2008. Isolation and variation in virulence of single-spore isolates of Plasmodiophora brassicae from Canada. Plant Dis. 92:456-462. 